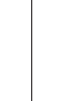

\section{Small Business Tax Regimes}

Jacqueline Coolidge and Fatih Yılmaz

Jacqueline Coolidge (jcoolidge@schoolbench .com) is a former World Bank staff member, and is now a consultant working primarily on tax, legal and regulatory reforms to improve the investment climate/business enabling environment. Fatih

Yılmaz(fatih.yilmaz@ tcmb.gov.tr), a former World Bank consultant, is currently an Economist at the Central Bank of the Republic of Turkey. Research for this note was supported by the World Bank Group's Trade and Competitiveness global practice.

\section{What Surveys Reveal about Tax System Use and Abuse}

\section{Simplified tax regimes for micro and small enterprises in developing countries are intended to facilitate voluntary tax compliance.}

However, survey evidence suggests that small business taxation based on simplified bookkeeping or turnover is sometimes perceived as too complex for microenterprises in countries with high illiteracy levels. Very simple fixed tax regimes not requiring any books or records tend to be overly popular but prone to abuse. System reforms would require more precise tailoring of the simplified regimes to their target beneficiaries, coupled with strong compliance management to detect and deter abuse.

The overall objective of simplified taxation for micro and small enterprises (MSEs) in developing countries is generally to facilitate voluntary tax compliance and remove obstacles in moving toward business formalization and growth. While the design of such simplified taxes varies by country, two main types of simplified regimes can generally be distinguished:

(1) Very simple lump sum or fixed amount taxes (also called "patents"), usually targeted at microenterprises, taking into account that such businesses are often operated by illiterate or semi-literate entrepreneurs.

(2) Presumptive profit taxes or single taxes (replacing a number of other taxes) based on turnover, either with the tax liability calculated as a percentage of turnover or with net profit calculated by applying a standardized cost deduction from turnover to account for business expenses.
A review of the operation of simplified tax regimes using results from the World Bank's Tax Perception and Compliance Cost Surveys in six developing countries revealed notable differences in the level of system acceptance and use. In addition, the results showed evidence regarding risks of system abuse, depending on the regime's design characteristics and application as well as country-specific characteristics. Despite the operation of a special simplified tax regime, in some cases small firms may be deterred from formalizing due to perceived excessive tax burdens, compliance costs, and risks (including risks of punishment for real or alleged non-compliance). In other cases, though, the overly generous design of a simplified regime may deter businesses from reporting growth and "graduating" into the general tax regime. Such risk factors and business attitudes have to 
be taken into account by policy makers in the system design exercise and should be updated over time as conditions change.

\section{Simplified MSE tax regimes in survey countries}

The World Bank surveys were conducted in Albania, Burundi, Nepal, South Africa, Ukraine, and the Republic of Yemen. They collected information about the use and abuse of simplified regimes, along with data on firm characteristics (size, sector, location, and so on). ${ }^{1}$ The countries had different kinds of simplified MSE tax regimes at the time of the survey (table 1).

\section{Although popular, compliance management is challenging for fixed tax regimes}

Fixed tax regimes (FTR) consistently show very high levels of usage, as they typically combine a rather low tax burden with minimal compliance costs. Overall, the reported use of fixed tax regimes among those businesses eligible in the survey countries was 98 percent in Albania, 92 percent in Burundi, 88 percent in Nepal, 93 percent in Ukraine (among sole proprietors), and 96 percent in the Republic of Yemen.

However, very low or even non-existent reporting requirements render system eligibility criteria hard to monitor. The risk of FTR abuse for tax revenue management increases with the size of businesses using the regime, so clear rules need to be introduced (and enforced). This will restrict system access to a core target group of subsistence-level enterprises (usually assumed to be operated by illiterate or semi-literate entrepreneurs). Survey responses strongly suggest, however, that this principle is frequently not followed in practice, and fixed tax regimes were often reported to be used by small or even mediumsized businesses, resulting in a risk of declining taxpayer participation in the general tax regime.

In some transition and developing countries, where fixed tax regimes initially were introduced with the objective of minimizing the burden on low-capacity tax administrations facing rapid growth of the taxpayer population in the micro business segment, the high popularity of the regimes among a large number of constituents made them politically difficult to remove (Engelschalk 2004; Bird and others 2008). This occurred even when the original rationale for introducing the system became less important as tax administration capacity was strengthened.

In practice, fixed tax regime thresholds are difficult to enforce because of the low documentation requirements of these regimes. The survey

\section{Table Simplified MSE tax regimes in survey countries}

\section{Fixed tax regime for Simplified tax regime for}

\begin{tabular}{lll} 
Country (survey year) & micro businesses & small business \\
\hline Yemen, Rep. (2007) & Yes & Turnover tax
\end{tabular}

\begin{tabular}{lll}
\hline Ukraine (2007) & Yes & Turnover tax
\end{tabular}

Burundi (2010) Yes Net income taxation based on simplified accounting.

\begin{tabular}{lll}
\hline Nepal (2010) & Yes & No \\
\hline South Africa (2011) & No & Turnover tax \\
\hline Albania (2012) & Yes & Net income taxation based on \\
& & simplified accounting.
\end{tabular}

Key eligibility criteria

Eligibility for a fixed tax regime is based on reported inability to keep books; fixed tax liability based on negotiations.

Fixed tax regime accessible for sole proprietors only; turnover tax only for legal entities. Fixed tax threshold is turnover below Ukrainian Hryvnia (UAH) 3 million (US $\$ 98,800$ ), with not more than 20 employees. The turnover tax threshold is turnover below UAH 5 million (US\$164,700), with a maximum of 50 employees.

Fixed tax threshold is Burundian Franc (BFr) 15 million $(\mathrm{US} \$ 12,000)$ for accommodation and services; BFr 20 million (US $\$ 16,000)$ for trade and manufacturing.

Regime threshold is Nepalese Rupee (NR) 2 million (US\$25,000). Eligible firms could pay fixed tax and also register for the value-added tax (VAT). Regime threshold is South African Rand (R) 1 million (US\$86,100). Fixed tax regime for businesses with turnover below Albanian Lek (LEK) 2 million (US\$15,900). Simplified accounting for businesses with turnover below LEK 8 million (US\$63,500) (thus, substantially exceeding the VAT threshold of LEK 5 million). 
evidence suggests that the risk of fixed tax regime abuse increases in two cases in particular: (i) the fixed tax regime threshold is not clearly defined or is inappropriately high; and (ii) the absence of an intermediate simplified small business tax regime forces small businesses to avoid growing, either by staying below the turnover threshold or by under-reporting turnover to tax authorities.

An example of the first case occurred in the Republic of Yemen, which had no clear FTR threshold but allowed any business that did not keep books of account to apply the fixed tax. ${ }^{2}$ The regime permitted the business to initially negotiate its tax liability with the tax authority. This tax liability was increased by a fixed amount each year, resulting in a low tax liability with long-term predictability. The survey provided strong evidence that the great majority of businesses used the fixed tax regime irrespective of the actual bookkeeping practice and capacity; in fact, about half of businesses reporting usage of the fixed tax regime also reported keeping regular books. Fortunately, such de facto "negotiated" tax regimes with nontransparent eligibility criteria are being phased out in most developing countries.

The second alternative was observed in Burundi (as of the time of the survey, before it enacted reforms). Small businesses with turnover above the fixed tax regime threshold could, in principle, apply simplified accounting rules; however, these accounting simplifications generally were perceived as not very different from the regular tax regime. Seeing no significant advantages, very few businesses (less than 1 percent) ever used this approach. Therefore, when faced with a choice between migrating downwards into the fixed tax regime with very low effective tax rates and a very simple administration, or complying with the regular tax regime, many small and even medium-sized businesses with a turnover (as reported in the survey) higher than the FTR threshold nevertheless reported using the FTR. Survey data suggest that about half of all tax-registered businesses used the FTR, although only 36 percent were actually eligible for it.

A similar disincentive for migrating out of the fixed tax regime exists in Albania. All small businesses in Albania are allowed at the beginning of the year to opt for the FTR. Only when at some point during the year their turnover exceeds the FTR threshold are they expected to shift to the simplified accounting regime. Similar to the situation in Burundi, the simplified accounting regime is not considered really attractive; therefore, such migration is not particularly popular.

\section{Small business turnover tax regimes not necessarily popular among targeted businesses}

Only three of the countries surveyed (South Africa, Ukraine [regime limited to legal entities], and the Republic of Yemen) operated turnover tax (TOT) regimes for small businesses, so the country analysis is therefore limited. However, substantial evidence exists to counter the frequent assumption that TOT regimes automatically become a widely used compliance simplification tool for small businesses. In fact, existing TOT regimes were ultimately not particularly popular in any of the countries surveyed. Use of TOT among those eligible was only around 7 percent in South Africa, under 30 percent in Ukraine, and under 5 percent in the Republic of Yemen.

The survey analysis suggested a variety of reasons why TOT regimes attract fewer taxpayers than might be expected.

In the case of Ukraine, the tax rates of the TOT regime are relatively high: the rate is 10 percent when the regime is applied to substitute for both income tax and VAT, and 6 percent when it substitutes only for income tax. Thus, the tax burden resulting from the application of the regime risks being viewed as unattractive for industries with relatively tight profit margins. In addition, there is some evidence (from sources other than the Tax Perception and Compliance Cost Surveys) that system competition has occurred between the TOT regime for legal entities and the fixed tax regime for individual entrepreneurs with a comparatively much lower tax liability. Although there was not much survey evidence of large-scale abuse of either simplified regime, the possibility of reducing tax liability by changing the legal status of the business to operate as sole proprietor rather than a legal entity seems to have contributed to more take-up of the fixed tax regime at the expense of the TOT regime. ${ }^{3}$

A clear case of system competition could be observed in the Republic of Yemen, where the lack of proper limitations in applying the fixed tax regime eroded the tax base of the TOT regime. As a result, in 2007 less than 5 percent of businesses opted for turnover taxation, primarily 
those businesses engaged in international trade (and not allowed to use the fixed tax regime).

In South Africa, the Revenue Service had initially considered setting different TOT rates for industry sectors depending on their average profitability. However, a closer examination of existing data did not reveal statistically significant differences in average profit margins between sectors (mostly because the variance within each sector was very high). The Revenue Service opted for a uniform progressive rate structure ranging from 1 percent up to 7 percent of turnover. Although the TOT liability for the majority of small businesses is considerably lower than in Ukraine, adoption of the regime was much less than anticipated. Registration numbers, which had been expected to exceed 40,000 within the first two years of system application, never rose above 8,000 . The great majority of taxpayers were clustered at the lower end of the distribution, thereby paying the lowest TOT rates.

Survey evidence indicates that an important lesson of the South African example is the critical importance of taxpayer outreach and information to explain the simplified tax regime and promote its use, particularly in encouraging informal businesses to become tax compliant. In South Africa, a deficient communications campaign associated with the introduction of the new TOT in 2008 failed to encourage many businesses to make use of the new regime. In a 2011 survey, the majority of micro, small, and medium enterprises (MSMEs) expressed confusion about whether they were even eligible for the regime. Over 40 percent responded "unsure" or "don't know," and almost half (46 percent) answered "no" - even though about 70 percent were in fact estimated to be eligible on the basis of turnover. ${ }^{4}$

\section{Abuse risks of presumptive tax regimes and ineffective enforcement}

Survey evidence suggests that fixed tax regimes generally have a higher risk of abuse, that is, use by non-eligible businesses, than TOT regimes. The evidence is clearest in the cases of Burundi and Nepal, but less obvious in the Republic of Yemen due to the non-transparent FTR threshold. Abuse levels among FTR users ranged from about one-quarter in Nepal to almost half in the Republic of Yemen, whereas abuse rates for those using TOT was below 20 percent in both South Africa and Ukraine (table 2).

The general tax policy approach, allowing lowcapacity, poverty-level microenterprises to pay a small fixed tax amount without any bookkeeping requirements and allowing small businesses to pay a simplified turnover tax based on minimal bookkeeping standards, appears reasonable. However, the high abuse rate, in particular of fixed tax regimes, should be a matter of concern in practice. While the revenue potential of fixed taxpayers is low, system abuse and the extension of a fixed tax regime to the taxpayer population above subsistence level create perverse incentives - a risk both for revenue generation and business growth and development. Tax policy makers and administrators need to consider how to mitigate these risks. On the tax policy side, the definition of sufficiently low and properly verifiable regime thresholds is a critical design task; on the administrative side, compliance management activities and control of (major) system abuse should extend to the micro-business segment.

Summary of estimates of use and abuse of simplified regimes among business taxpayers

\begin{tabular}{|c|c|c|c|c|c|c|}
\hline Country & $\begin{array}{l}\text { Type of simplified } \\
\text { regime analyzed }\end{array}$ & $\begin{array}{l}\text { Percentage of all } \\
\text { firms that are eligible } \\
\text { for the regime }\end{array}$ & $\begin{array}{l}\text { Percentage of all } \\
\text { firms that use } \\
\text { the regime }\end{array}$ & $\begin{array}{l}\text { Percentage of firms } \\
\text { eligible for the regime } \\
\text { that use it }\end{array}$ & $\begin{array}{l}\text { Estimated abuse } \\
\text { (percentage of } \\
\text { all firms) }\end{array}$ & $\begin{array}{l}\text { Estimated abuse } \\
\text { (percentage of firms } \\
\text { using the regime) }\end{array}$ \\
\hline Yemen, Rep. & FTR & 47 & 94 & 96 & 47 & 48 \\
\hline Burundi & FTR & 36 & 50 & 92 & 14 & 34 \\
\hline Nepal & FTR & 86 & 80 & 88 & $4^{a}$ & $26^{a}$ \\
\hline Albania & FTR & 58 & 58 & 98 & $<2^{\mathrm{a}}$ & $<1^{a}$ \\
\hline South Africa & TOT & 69 & 7 & 8 & 1 & 18 \\
\hline Ukraine $^{b}$ & TOT & 60 & 34 & 29 & 5 & 16 \\
\hline
\end{tabular}

Source: Coolidge and YIImaz 2015.

Note: FTR abbreviates fixed tax regime; TOT abbreviates turnover tax

a. Abuse of the FTR in Albania and Nepal was probably substantially higher, taking into account average estimated levels of under-reporting turnover in the survey.

b. Non-agricultural legal entities. 
In practice, compliance management frequently seems insufficient even in the small business segment. Evidence suggests that tax administrations in almost all countries surveyed failed to put into place risk-management strategies targeted at detecting abuse of simplified tax regimes. Instead of concentrating scarce audit resources on cases of high system abuse risks, most of the surveyed countries seemed to follow an approach of merely ensuring relatively broad audit coverage of the MSE segment. In line with international good practice, the percentage of businesses audited in the MSE segment was generally lower than in the large and medium business segments. However, a risk-based small business audit approach seemed to be lacking.

Surveys identified no statistically significant correlation between the level of inspections and the level of system abuse.

\section{Conclusion}

It has been well accepted theoretically that presumptive taxation should be designed to address the highest priority problems of taxing MSMEs in developing and transition countries. These priorities are likely to change as countries grow and capacity improves both in the public and the private sectors. Simplified tax regimes should be periodically reformed to ensure they continue to address priority needs under changing circumstances. Surveys of small businesses focusing on education levels, bookkeeping practices, use of bank accounts, and similar objective variables may help inform the key parameters of simplified regimes.

Data from taxpayer surveys suggest that fixed tax regimes may cause significant damage in eroding the base of the general or turnover-based small business tax regimes, which needs to be taken into account in a cost-benefit analysis of these regimes.

Despite the risk, the data from Burundi, Nepal, and the Republic of Yemen suggest a continuing need for a fixed-tax regime for true microenterprises in low-income, low-capacity countries, as many such businesses are unable to practice bookkeeping (for example, in cases where national adult literacy rates are under 90 percent) and have net incomes at or near the poverty threshold. Even for these countries, however, it may be beneficial to place more emphasis on the design of simplified regimes appropriate for small businesses yielding incomes above poverty levels. Such businesses should be required to keep basic books (for example, reports of daily sales, although not necessarily the details of every transaction) and to pay tax based on turnover. Thresholds should be set by taking into account correlations between turnover, on the one hand, and literacy and (roughly) estimated net income, on the other. The thresholds should be revised periodically to keep them in line with their target populations. At the same time, small businesses should be offered training in basic bookkeeping and preparation of simple tax returns and other aspects of realistic tax compliance.

The case of South Africa illustrates the need for targeted outreach and education campaigns aimed at micro and small enterprises so that they can gain a better understanding of the options available to them. The emphasis in South Africa has arguably been too heavily in favor of "deterrence" of businesses that might be ineligible to use the regime. In this context, the Revenue Authorities' information has probably overemphasized the topic of ineligibility, while not sufficiently informing and encouraging eligible small businesses about the opportunity and benefits of the TOT regime.

More broadly, it appears that in many cases "simplified" regimes that require bookkeeping tend to be perceived as still overly complex and therefore unpopular. These will require more encouragement. "Patent" or fixed-tax regimes appear to be overly popular, but prone to abuse, and may need to be more restricted. Compliance simplifications for small businesses which are limited in scope to just minor simplifications in the tax accounting requirements - but do not also simplify tax calculation and payment obligations - are not seen as a real relief, and they seem to be poorly accepted. Beneficial reforms would require more precise tailoring of the simplified regimes to their target beneficiaries (which will probably shift over time), coupled with well-targeted compliance management to detect and deter abuse. 


\section{Notes}

1. For a complete description of the surveys, see Coolidge (2012). The surveys all included at least several hundred active business taxpayers, and were based on a stratified sample from the relevant tax authorities. The detailed draft country reports are available from the authors on request.

2. This was the case at the time of the survey; more recently, the Republic of Yemen has enacted fundamental reforms of its MSME tax regime.

3. There is also evidence that many businesses use other ploys, such as contracting of "sole proprietors" instead of employees, or splitting up a business into two or more entities in order to qualify for the presumptive regime (IFC 2009).

4. A small proportion of these generally eligible businesses could indeed have been legally excluded, which could be based on other criteria limiting system accession in case of certain activity types, or close links to larger businesses. See Smulders and others (2012).

\section{References}

Bird, Richard M., Jorge Martinez-Vazquez, and Benno Torgler. 2008. "Tax Effort in Developing Countries and High Income Countries: The Impact of Corruption, Voice and Accountability." Economic Analysis and Policy 38(1): 55-71.

Coolidge, Jacqueline. 2012. "Findings of Tax Compliance Cost Surveys in Developing Countries.” eJournal of Tax Research 10(2): 250-87.

Coolidge, Jacqueline and Fatih Yılmaz. 2015. "Simplified Small Business Tax Regimes in Developing Countries: Empirical Evidence of Use and Abuse." In Tax Simplification, edited by Chris Evans, Richard Kreve, and Peter Mellor. Alphen aan den Rijn: Kluwer Law International.

Engelschalk, Michael. 2004. "Creating a Favorable Tax Environment for Small Business.” in Taxing the Hard-to-Tax: Lessons from Theory and Practice, edited by James Alm, Jorge Martinez-Vazquez, and Sally Wallace, 275-311. Oxford: Elsevier.

IFC (International Finance Corporation). 2012a. "Albania Tax Compliance Cost Survey." Unpublished note. 2012b. "Le Coût de la Mise en Conformité avec la Réglementation Fiscale du Secteur Formel et la Perception de la Fiscalité par le Secteur Informel au Burundi."

-2012c. Nepal Tax Compliance Cost Survey

Report. Available at: https://www.wbgin vestmentclimate.org/publications/loader .cfm?csModule=security/getfile\&pageid $=33942$ 2009. The Costs of Tax Compliance in Ukraine.

Available at: http://www.ifc.org/wps/wcm/connect /725f0b804b5f7ae59f06bf6eac26e1c2/UTCCS_eng .pdf?MOD=AJPERES\&CACHEID $=725 \mathrm{f0b} 804 \mathrm{~b} 5 \mathrm{f} 7 \mathrm{ae} 5$ 9f06bf6eac26e1c2.

—. 2008. "Yemen Tax Cost of Compliance Survey." Unpublished note.

Khwaja, Munawar Sultan, Rajul Awasthi, and Jan Loeprick. 2011. Risk-Based Tax Audits: Approaches and Country Experiences. Washington, DC: World Bank.

Smulders, S., M. Stiglingh, R. Franzsen, and L. Fletcher. 2012. "Tax Compliance Costs for the Small Business Sector in South Africa." EJournal of Tax Research $10(2): 182-226$.

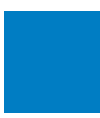
contact Jenny Datoo, managing editor, Room F 5P-504,

The World Bank, 1818 H Street, NW, Washington, DC 20433.

Telephone:

00I 2024736649

Email:

jdatoo@worldbank.org

Produced by Carol Siegel

Printed on recycled paper 